ERRATUM

\title{
Effects of teriparatide in postmenopausal women with osteoporosis pre-treated with bisphosphonates: 36-month results from the European Forsteo Observational Study
}

F Jakob, H Oertel ${ }^{1}$, B Langdahl ${ }^{2}$, O Ljunggren ${ }^{3}$, A Barrett ${ }^{4}$, D Karras ${ }^{5}$, J B Walsh ${ }^{6}$, A Fahrleitner-Pammer ${ }^{7}$, G Rajzbaum ${ }^{8}$, C Barker ${ }^{4}$, W F Lems ${ }^{9}$ and F Marin ${ }^{4}$

The authors and the journal apologise for errors that appeared in Figure 2 of this article published in the January issue, Vol 166, pp 87-97. The errors relate to the number of asterisks given to represent the $P$-values for odd ratios $(\mathrm{OR})$ of the comparisons with 0 to $<6$ months interval. In Figure $2 \mathrm{a}$, the correct data should read as

6 to $<12$ months vs 0 to $<6$ months: OR 0.66 (95\% CI: 0.45 to 0.98$)^{*}$

12 to $<18$ months vs 0 to $<6$ months: OR 0.63 (95\% CI: 0.41 to 0.96$)^{*}$

and in Figure 2b, the correct data should read as:

12 to $<18$ months vs 0 to $<6$ months: OR 0.38 (95\% CI: 0.18 to 0.82$)^{*}$

and not as published. The correct figure and legend is given below.

European Journal of Endocrinology 166563

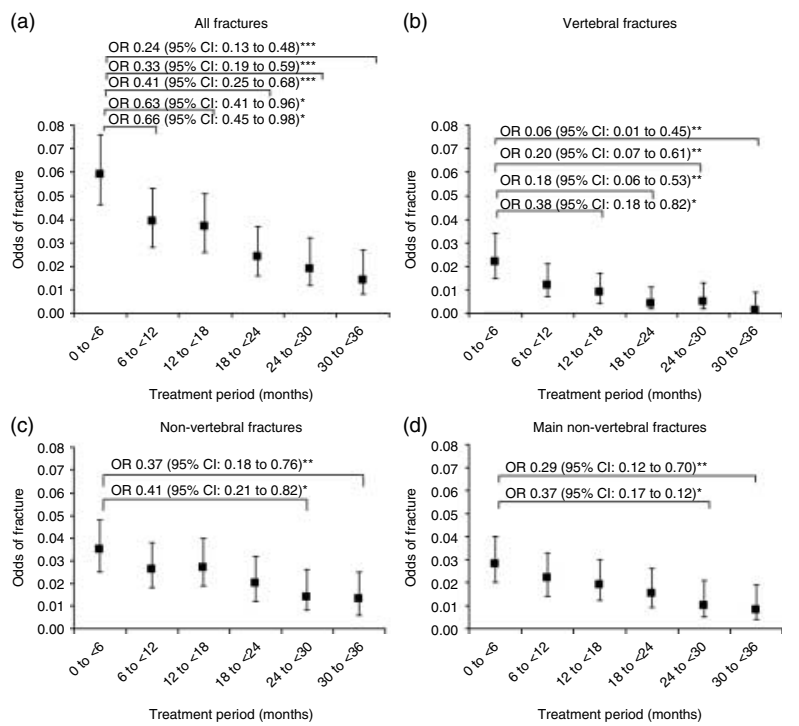

Figure 2 Risk of fracture (adjusted odds with 95\% confidence intervals (Cls)) by fracture type: (a) all fractures pooled, (b) clinical vertebral, (c) non-vertebral, and (d) main non-vertebral, in each 6-month interval for the prior bisphosphonate user group. Note: Odds ratios (OR) and $95 \%$ confidence intervals $(\mathrm{Cl})$ for the comparison with the first 6 months of treatment are given where significant. ${ }^{\star} P<0.05$; ${ }^{\star \star} P<0.01$;

${ }^{* * \star} P<0.001$ vs. 0 to $<6$ months interval. Main non-vertebral fractures includes forearm/wrist, hip, humerus, leg and sternum/ribs. 